\title{
8
}

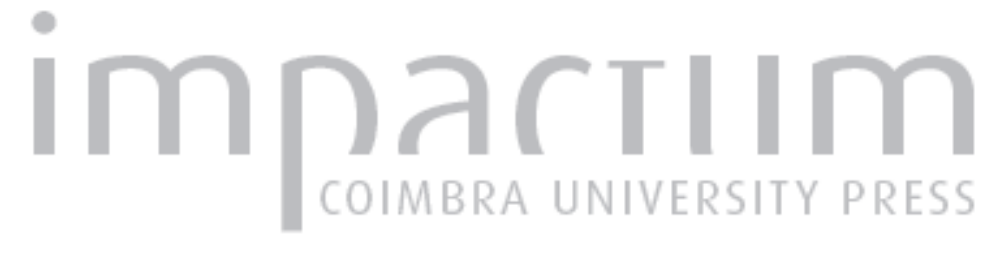

\section{Aspectos de Conimbriga tardo-antiga}

\author{
Autor(es): $\quad$ Man, Adriaan De
}

Publicado por: Faculdade de Letras da Universidade de Coimbra

URL persistente:

URI:http://hdl.handle.net/10316.2/39987

DOI:

DOI:https://doi.org/10.14195/0870-4112_2_19

Accessed : $\quad$ 26-Apr-2023 16:33:13

A navegação consulta e descarregamento dos títulos inseridos nas Bibliotecas Digitais UC Digitalis, UC Pombalina e UC Impactum, pressupõem a aceitação plena e sem reservas dos Termos e Condições de Uso destas Bibliotecas Digitais, disponíveis em https://digitalis.uc.pt/pt-pt/termos.

Conforme exposto nos referidos Termos e Condições de Uso, o descarregamento de títulos de acesso restrito requer uma licença válida de autorização devendo o utilizador aceder ao(s) documento(s) a partir de um endereço de IP da instituição detentora da supramencionada licença.

Ao utilizador é apenas permitido o descarregamento para uso pessoal, pelo que o emprego do(s) título(s) descarregado(s) para outro fim, designadamente comercial, carece de autorização do respetivo autor ou editor da obra.

Na medida em que todas as obras da UC Digitalis se encontram protegidas pelo Código do Direito de Autor e Direitos Conexos e demais legislação aplicável, toda a cópia, parcial ou total, deste documento, nos casos em que é legalmente admitida, deverá conter ou fazer-se acompanhar por este aviso.

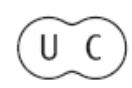


REVISTA DA FACULDADE DE LETRAS U N I VERS I A D E D E C O I M B RA 


\section{Adriaan De Man}

Universidade de Coimbra

Aspectos de Conimbriga Tardo-Antiga

Após o grande ciclo renovador de Flauia Conimbriga, o urba nismo da cidade não voltou a beneficiar de uma nova planificação, pelo menos até o momento em que se optou pela drástica ablação de parte sig nificativa da área construida, para edificar a muralha defensiva. O período de tempo que medeia entre estes dois momentos deixou pouca informação concreta; poderíamos pressupor uma certa inércia arquitectónica, pelo menos na área escavada, mas a manutenção funcional das termas de Tra jano e do forum pode significar apenas que não havia motivo óbvio para transformar este esquema durante aproximadamente uma centúria. Nas insulae, por seu turno, distinguem-se sucessivas fases de ocupação, e as Fouilles oferecem uma panorâmica evolutiva até o século IV ${ }^{1}$. A ideia que fica vai ao encontro de uma imagem de pequenas alterações a nível da propriedade privada, e não da organização estrutural. Na insula a norte das termas, por exemplo, verifica-se que muitos dos compartimentos, a dada altura, tendem a separar-se do imóvel original, ou então mudam de função. A do vaso fálico é sujeita ao mesmo género de intervenção, sendo possível distinguir duas fases de transformações. Regra geral, a constante sobreposição de pavimentos e a frequência com que certos muros são acrescentados ou obliterados fazem acreditar numa sucessão de proprietá rios e de pequenos projectos de índole privada. Sempre na delimitação flaviana. Um paralelo emeritense ${ }^{2}$ pode oferecer uma explicação comple mentar para a desconexão da domus, e a respectiva subdivisão em habita ções menores. A tendência desarticuladora da casa senhorial tem na sua origem um declínio na prosperidade dos mais ricos, mas as transforma ções também apontam para o desenvolvimento do pequeno negócio. De destacar é a aparente vivacidade comercial neste intervalo cronológico, a

1 J. Alarcão e R. Etienne, Fouilles de Conimbriga /, L'architecture (Paris, Diffusion de Boccard 1977) 155-163.

2 M. Alba Calzado, 'Datos para la reconstrucción diacrónica del paisaje urbano de Emerita: Las calles porticadas desde la etapa romana a la visigoda, Mérida - Excavaciones Arqueológicas', Memoria (2000) $\mathbf{n}^{\circ}$ 6, (Consorcio Ciudad monumental de Mérida, Mérida 2002) 371-396.

\section{Faculdade de Letras Universidade de Coimbra}


deduzir da manutenção de tabernae com nítidos níveis de funcionamento, facto observado com alguma admiração por quem escavou o sítio. Neste século IV, les gens de Conimbriga ne paraissent pas manquer d'activité économique ${ }^{\wedge}$. E verdade que esta situação, pelo menos em parte, seria resultado da conhecida petrificação social que, a partir de Diocleciano, submetia totalmente o trabalhador a um local, a um ofício e a um patrão.

Mas é também nos inícios desta centúria que se erige a muralha defensiva. No último quartel do século III, Domício Aureliano deu ordem às cidades do Império para que criassem muralhas de Protecção e para se prepararem para contar apenas com as suas próprias forças ${ }^{4}$, e começou por fazê-lo na própria Roma5: muros urbis Romae dilatauit, segundo a Historia Augusta ${ }^{6}$. Idêntica ideia está expressa no Livro dos Césares ${ }^{7}$ e no Breviário de Eutrópio $^{8}$ Duas águas-fortes de Piranesi ilustram a muralha aureliana $^{9}$, e as respectivas torres, apesar de mais complexas, asseme lham-se, no seu conceito, às de Conimbriga. Era o prenúncio de um fenómeno cada vez mais nítido. A polarização do poder ia-se tornando visível, enquanto as cidades se retraíam num perímetro defensivo, ruralizando-se; a ciuitas, enquanto núcleo elementar da romanidade, atrofiara, e, nas palavras de Pierre Grimai ${ }^{10}$, desaparecera com ela a liberdade e a paz. Algo parecido ocorreu também em Conimbriga. A muralha tardia foi projectada e executada de forma muito rápida, provavelmente no primeiro quartel do século IV ${ }^{11}$. O que, aliás, está em consonância com o que se

5 Alarcão e Etienne, op eit, 162.

4 I. Montanelli, História de Roma: Da fundação à queda do Império (Lisboa, Edições 70 2002) 279.

5 F. Paschoud, Zosime, Histoire Nouvelle (Paris, Les Belles 1996), 131 ; N. Christie, Construction and deconstruction: reconstructing the late-roman townscape, Towns in Decline, $A D 100$ - 1600 (Ashgate, Aldershot / Vermont 2000) 55; Montesquieu, Considerações sobre as causas da grandeza e decadencia dos Romanos (Lisboa, Assírio \& Alvim 2002) 168, nota 44.

${ }^{0}$ Historia Augusta, Dims Aurelianus XXI, 9, vide também XXXIX, 2.

7 Aurelius Victor 35, 7: muris Vrbem [...] circumsaepsit, vide P. Dufraigne, Aurelius Victor - Livre des Césars (Paris, Les Belles Lettres 1975) 44-45.

8 Eutropius IX, 15: Vrbem Romam muris firmioribus cinxit, vide J. Hellegouarc'h, Eutrope - Abrégé d'Histoire Romaine (Paris, Les Belles Lettres 1999) 121.

9 L. Ficacci, Piranesi, Catálogo completo das águas-fortes (Köln, Taschen 2001$) 177$.

10 P. Grimai, A civilização romana (Lisboa, Edições 70 1993) 273.

11 V. H. Correia, Nouvelles recherches à Conimbriga, Itinéraires Lusitaniens Trente années de collaboration archéologique luso-française (Paris, Diffusion de Boccard 1997)40.

\section{Faculdade de Letras | Universidade de Coimbra}


passou noutras cidades peninsulares, quer se tenha construído de raiz, quer sobre as muralhas honoríficas ${ }^{12}$, solução parcialmente adoptada em Conimbriga. É provável que tenha havido uma participação ou incentivo indirecto por parte do governo central na obra. Olhando para o quadro geral, não vemos como teria sido possível fortificar umas cento e oitenta cidades, entre Gália, Espanha e Itália ${ }^{13}$, em tão pouco tempo, se se tra tasse de apenas uma recomendação sem apoio. Numa época de grave des valorização monetária, é possível que esse apoio tenha sido directo, ou seja, que as muralhas tenham sido construídas ou orientadas pelo exército. Das três colinas ocupadas passou-se de novo para apenas uma, e a solução considerada mais vantajosa foi fechar a muralha sobre o seu limite, mas a parte em que houve integração da muralha honorífica teve de sofrer um reforço; ela não tinha sido planeada para servir de defesa real. $\mathrm{O}$ seu enchimento é composto por todo o tipo de material reutilizável, unido por um cimento. Há cidades em que estes spolia, muitas vezes epígrafes ou esculturas, eram inseridas na muralha enquanto relíquias do passado ${ }^{14}$, conquanto a preocupação em organizá-las e expô-las enquanto curiosida des não nos parece evidente em Conimbriga. Se bem que não possamos afirmá-lo com certeza, porque o núcleo é o único resto da maior parte da muralha não restaurada. Não duvidamos que ela tenha sido efeito directo de directivas imperiais, preocupadas com a defesa, mas há pormenores na construção que fazem pensar numa tentativa paralela de manter um determinado estatuto, nomeadamente esta resistência à adopção de torres verdadeiramente defensivas. Parece que se concordou, relutantemente, com a construção da muralha, mas em condições que permitiram uma espécie de engrandecimento do anel honorífico. Outra indicação nesse sentido é a falta de cuidado que houve na fortificação da parte sul da cidade. Etienne e Alarcão chamam-lhe confiança cega no declive, mas é provável que, mais do que isso, lhe seja de procurar outra razão: desse lado não havia portas, e portanto também não havia visitantes. Acredita mos que, para o habitante de Conimbriga, a muralha tanto significou monumentalização como fortificação, e enquanto a primeira acção tinha

12 C. Fernandez Ochoa, e A. Morillo Cerdan, Fortificaciones urbanas de época bajoimperial en Hispania. Una aproximación crítica (segunda parte) (Madrid, CuPAUAM 18 1992); Cepas Palanca (Adela), 'La ciudad tardía en Hispania: problemas metodológicos', in Actas do $I^{o}$ Congresso de Arqueologia Peninsular, Actas Vil, Trabalhos de Antropologia e Etnologia, vol. 35 (3) (Porto, Sociedade Portuguesa de Antropologia e Etnologia 1995).

13 S. Johnson, Late Roman Fortifications (Londres, B T Batsford 1983) 10.

14 Christie op. eit, 59. 
um efeito imediato e visível, a segunda baseava-se numa ideia abstracta, demasiado longínqua.

O anfiteatro, parcialmente reutilizado, foi considerado dispen sável, contudo teria sido possível aproveitar o monumento na própria muralha, já que esta acabou por lhe passar por cima. $O$ anfiteatro de Nîmes foi militarizado e transformado em reduto defensivo ${ }^{15}$. Apesar de haver evidência esporádica da continuação de jogos em determinadas cidades, a tendência iria, gradualmente, para o seu desaparecimento, não em pequena medida devido à posição da Igreja ${ }^{16}$, mas também por razões económicas. Um exemplo típico da nova situação é a construção de uma igreja no anfiteatro de Tarragona, no final do século VI ${ }^{17}$. De facto, desde finais do século IV, os munera de gladiadores foram desaparecendo, e o Codex Theodosianus é consensualmente tido como prova de que os jogos teriam desaparecido nos primórdios do século $\mathrm{V}$, com um ultimo espasmo no anfiteatro flávio da própria Roma ${ }^{18}$. Torna-se cada vez mais notorio o apetite pelos edificios públicos redundantes ou em desuso ${ }^{19}$. Os fundos pessoais, municipais e também imperiais continuavam a escassear, e é esclarecedor que a partir de Diocleciano e Constantino comecem a rarear as inscrições que mencionam a construção de novos edifícios públicos, sem contar com as eclesiásticas ${ }^{26}$. De facto, o contraste entre o impulso construtivo da autoridade episcopal e a decadência dos imóveis parti culares é muito notório nos séculos VI e VII ${ }^{21}$, e enquanto ocorre uma homogeneização ruralizante no grosso do povo hispano-romano, a Igreja repõe, como pode, o orgulho urbano.

15 A. Dupont, Les cités de la Narbonnaise Première depuis les invasions germaniques jusqu'à l'apparition du consulat (Nîmes 1942)229.

16 De Eusébio de Cesareia a Santo Agostinho, no seguimento da condenação aberta dos cruenta spectacula, por parte de Constantino, que aliás deixou rapidamente de surtir efeito.

17 P. D. King, Law and society in the visigothic kingdom (Cambridge, University Press 1972)202.

10 R. Tẹja 'Los juegos de anfiteatro y el Cristianismo', Coloquio Internacional El Anfiteatro en la Hispania Romana, Junta de Extremadura (Mérida 1994) 69.

16 A. M. Diogo e L. Trindade, 'Ânforas e sigillatas tardias (claras, foceenses e cipriotas) provenientes das escavações de 1966-67 do teatro romano de Lisboa', Revista Portuguesa de Arqueologia, 2.2 (1999) 87; Christie, op. cit., 63.

70 G. Alföldy Urban Life, Inscriptions and Mentality in Late Antique Rome. Urban centers and rural contexts in Late Antiquity (East Lansing, Michigan State University Press 2001) 11

21 Alba Calzado, op cit., 372.

\section{Faculdade de Letras Universidade de Coimbra}


A recorrência à demolição dos edifícios extramuros parece, por isso, menos prova de decadência terminal e de pânico mal orientado, dando lugar a uma perspectiva de mudança de ânimo perante a res publica. Se também as casas, as termas e até as necrópoles são desmonta das é porque os materiais são utilizados para construir noutro lado, neste caso em projectos privados e na cintura defensiva, e não por os habitantes terem desenvolvido um espírito destruidor repentino. As termas do aque duto, junto à porta de Aeminium, são uma reconstrução, mais modesta, é certo, de um complexo prévio ${ }^{22}$ *. Pressupõe-se uma gestão consciente, até porque se multiplicam situações semelhantes, na Hispania e na Gallia. Quem geria uma cidade, neste século IV, continuavam a ser os cines, mas a designação já não se aplicava no sentido clássico; agora, circunscreviase aos membros da ordo curiae $^{22}$. A magistratura deixara de ser uma posição cobiçada pelos clarissimi, cuja tendência de abandono da cidade (e subsequente transformação em potentes rurais) obrigou a que o governo municipal fosse desempenhado, doravante, pelos que restavam. O que numa pequena cidade provincial significava que a actividade só podia estar nas mãos de uma classe média, de comerciantes. Só que, essencialmente a partir dos Severos, a posição do magistrado passara de benfeitor supostamente desinteressado a colector de impostos. Idácio, ao mencionar o primeiro ataque suévico de 465, refere que a família de Cantaber foi feita cativa ${ }^{24}$. Parece óbvio que se tratava da principal famí lia local, e que, de uma forma ou de outra, ela se encontrava ligada à administração. Haveria, portanto, uma linhagem a dirigir Conimbriga, o que está em consonância com uma série de directivas de Constantino, que tornaram (obrigatoriamente) hereditário o cargo de curial $^{25}$. Se a evolução local seguiu uma mesma tendência geral, os magistrados alto-imperiais foram-se retraindo para o territorium da cidade, tentando escapar às cres centes obrigações fiscais, e dando origem a pequenas bolsas rurais, em torno das suas uillae. A casa senhorial do Rabaçal já não teria a mesma

22 V. H. Correia e M. P. Reis, 'As termas de Conimbriga: tipologias arquitectónicas e integração urbana1, in I! Coloquio Internacional de Arqueología en Gijón, Termas romanas en el Occidente del Imperio (Gijón, VTP Editorial 2000) 278; T. C. Coelho, Conimbriga, Termas do aqueduto. Integração urbana. Estudo Arquitectónico. Dissertação de Mestrado em História da Arte (Lisboa, Faculdade de Ciências Sociais e Humanas, Universidade Nova de Lisboa, tese policopiada 1993).

22 C. Sánchez - Albornoz, 'Estudios Visigodos\Stiidi Storici 78-79 ( 1971 ) 17.

24 Idácio CCCXI, 229; Sueui, Conimbricam dolose ingressi, familiam nobilem Cantabri spoliant et captiuem abducunt matrem cum filiis, vide A. Tranoy, Hydace Chronique, Sources Chrétiennes (Paris, Les Editions du CERF 1974).

25 Sánchez - Albornoz, op. cit., 20. 
relação de subordinação estrutural com Conimbriga do que aquela que existira por parte de uma qualquer uilla clássica. O seu proprietário encontrava-se provavelmente isento de taxas e impostos; a partir do século IV, o detentor de um título nobiliárquico não se sujeitava aos uectigalia, apesar de, em 398, Honorio ter abolido a glebalis collatio ${ }^{26}$, o privilégio fiscal que beneficiara senadores e decuriões durante séculos. Ao anular uma isenção, concedia-se, portanto, outra. Serão os Cantabri, então, produto da nova civilidade tardia, que veio substituir a magistratura clássica? Possivelmente, mas afigura-se-nos verosímil que a relação da ciuitas com o seu territorium não se tornara tão hermética e mutuamente exclusiva como os modelos teóricos fazem crer. Convém recordar que a elite conimbrigense sempre foi constituída por indígenas romanizados, e custa apelidá-los de clarissimi, em oposição aos seus concidadãos.

O concílio episcopal de Mérida decorreu em 666, e estava pre sente Cantaber Conimbriensis episcopus ${ }^{11}$. Significa isto que, durante pelo menos dois séculos, esta dinastia local se manteve na vanguarda do poder. Poderá a menção à nobre família de Cantaber $^{28}$, por parte do bispo de Chaves, ser entendida como indício de que, já nessa altura, ela era tida como próxima da Igreja, sua promotora ou protectora? A casa que se con vencionou atribuir a Cantaber fica adjacente à basílica paleocristã, apesar de ser praticamente impossível ter havido uma ligação estrutural entre ambas as construções. Não acreditamos que o adjectivo nobile se refira a um estatuto jurídico, mas antes a um estado de graça, perante uma Igreja agradecida. Mas é igualmente possível que a nobreza dos Cantabri tenha de ser levada à letra; conforme o Império ia avançando no tempo, tornouse quase uma obsessão para os provinciais a aquisição de títulos nobiliár quicos, e os imperadores, de início, distribuíam-nos à vontade. A situação tornou-se rapidamente problemática, não em pequena medida devido à isenção fiscal que a posição implicava. Foi implementada uma série de medidas limitativas, até que em 390 se subtraiu o carácter hereditário aos títulos, exceptuando no grau mais elevado, o dos illustres. Teodósio II acabou por limitar o acesso à nobreza aos de origem curial $^{29}$, processo

2^ Codex Theodosianus 6, 2, 21; vide J. M. Blazquez, Economia de la Hispania Romana (Bilbao, Ediciones Najera 1978) 599.

77

J. Vives, Concilios visigóticos e hispano-romanos (Barcelona - Madrid. Consejo Superior de Investigaciones Científicas 1963) 28, 19.

78 e

78 e não à "família do nobre cantabro", como na incorrecta tradução de Cardoso.

F. F. Abbott e A. Ch. Johnson, Municipal Administration in the Roman Empire

(New York, Russel \& Russel 1968) 205-206.

Faculdade de Letras | Universidade de Coimbra 
que, pouco tempo depois, também ficou sem efeito, retirando deste modo um dos últimos atractivos a uma posição que se transformara num fardo.

Tornou-se, de uma maneira geral, muito difícil recrutar diri gentes municipais, chegando-se a situações caricatas. Uma disposição de 415 permite inferir que existiam cidades sem magistrados ${ }^{30}$, e há casos de governadores provinciais a condenarem pessoas a pertencerem à ordo curiae $^{31}$, muito embora isto só se aplicaria a quem lhe tinha tentado esca par, e não a um criminoso comum. Uma boa forma de evasão individual às permanentes intromissões por parte do Estado era ingressar na hierar quia eclesiástica, cujos membros estavam isentos de obrigações fiscais. Os curiales, claro, aderiram em bloco, o que forçou Constantino a revogar a sua própria legislação, sob pena de ficar a comandar um império sem cidades. De qualquer modo, a propriedade privada dos magistrados aca bou por ser "nacionalizada", mas gerida por eles enquanto corpo diri gente, o que deve ter constituído uma boa dissuasão para potenciais desertores.

A situação militar, em termos estratégicos puramente romanos, dependia do estado da Legio VII Gemina, que, aquartelada há demasiado tempo, estava em vias de desintegração. Muitas das unidades referidas na já tardia Notitia Dignitatum podem constituir corpos simbólicos, na medida em que se recorreu a tropas privadas aquando da abertura das passagens pirenaicas, por consentimento dos Honoriaci germânicos, aos primeiros bárbaros ${ }^{32}$. De qualquer modo, a nova organização constantina apoiava-se em exércitos de comitatenses supostamente móveis ${ }^{33}$. Estas tropas, criadas já por Diocleciano, em oposição aos limitanei ou riparien $\boldsymbol{s e s}^{34}$, ficaram acantonadas em cidades que, à partida, não as desejavam. Constantino foi muito criticado por ter renunciado à defesa das fronteiras, instalando os soldados em cidades que não precisavam deles, privando de ajuda aqueles que estavam sob a ameaça dos Bárbaros ${ }^{35}$. Esta dispersão 30 Codex Theodosianus VIII, 12, 8; vide também Sánchez- Albornoz, op. eit., 32,
nota 23.

31 Declareuil apud Abbott e Johnson, op. cit., 207.

32 R. Macmullen, Soldier and Civilian in the later Roman Empire (Massachusetts, Harvard University Press 1963) 139-140.

R. S. O. Tomlin, Notitia Dignitatum, tam ciuilium quam militarium, Aspects of the Notitia Dignitatum (Oxford, BAR Supplementary Series 15, 1976) 189.

1974)277.

${ }^{3 \wedge}$ M. Grant, The army of the Caesars (Worcester/London, The Trinity Press

${ }^{35}$ Zósimo II, 34, vide Paschoud, op. cit. 107. 
estacionária fez certamente perder o sentido de coesão, de camaradagem e de belicosidade ${ }^{36}$. Mas há, por outro lado, indicações de que parte das unidades tenha mantido alguma da sua pretendida flexibilidade, ainda que também Montesquieu associe a dispersão dos meios militares a uma con dição de decadência: quando Roma passou a contar só com maus exérci tos, viu-se obrigada a fortificar um território que a fronteira já não defendia, com mais praças e menos forças, mais retiradas e menos segurança ${ }^{\wedge}$. O limes, enfraquecido, deixara de existir enquanto tal, e a partir dos inícios do século $\mathrm{V}$ já não se investe em fortalezas, mas em pequenas torres, por vezes construídas nalgum canto do bastião primitivo ${ }^{38}$. O que, em Conimbriga, pode ter acontecido no bico da muralha. Pudemos obser var que o muro que isola esta área não foi apenas adossado à muralha exterior; é-lhe contemporâneo porque um dos cantos, apesar de já deslo cado, demonstra um entrelaçamento estrutural. Se este muro foi cons truído aquando da reconversão da muralha augustana, ele integra-se, por conseguinte, no plano geral de defesa urbana. Repare-se nas disposições teodosianas que obrigam os cidadãos a participar nos trabalhos, e também nas que regulamentam a respectiva supervisão, a cargo das autoridades provinciais ${ }^{39}$.

Parece-nos evidente que o desaparecimento da VII legião, que simplesmente deixa de ser mencionada, seja correlativo à formação das unidades comitatenses. Alberto Balil apontou a contínua criação de Septimani a partir de coortes legionárias ${ }^{40}$, e a requisição de tropas cen trou-se essencialmente no desmembramento das antigas unidades. A nova organização militar tomou forma nos primeiros anos do século IV, e isso significa que as unidades construídas sobre fracções das legiões altoimperiais surgiram, no máximo, duas décadas após a directiva fortificadora de Aureliano, num mesmo espírito reorganizador. Mas a presença de

36 [Constantino] impôs às cidades, que eram pacíficas, a desordem soldadesca (o que as tornou, aliás, na sua maioria desertas), deixou amolecer os soldados que se davam aos espectáculos e a uma vida confortável, e, numa palavra, foi ele mesmo a origem e a razão da ruína do Estado que nos aflige ainda hoje.", ibidem.

${ }^{37}$ Montesquieu, op. cit.. 168.

$-30$

Z. Visy, Towns, Vici and Villae: Late Roman Military Society on the Frontiers of the Province Valeria, Urban Centers and Rural Contexts in Late Antiquity (East Lansing, Michigan State University Press 2001) 168.

${ }^{39}$ Blazquez, op. cit., 475.

49 A. Balil, La defensa de Hispânia en el Bajo Imperio. Amenaza exterior e inquietud interna, Legio Vil Gemina (León, Cátedra de San Isidoro - Instituto Leones de Estudios Romano-Visigoticos 1970) 612-613.

\section{Faculdade de Letras | Universidade de Coimbra}




\section{Aspectos de Conimbriga Tardo-Antiga}

tropas numa região começava a não significar Protecção automática para as cidades, e isso também se aplicava à Lusitania. Dos grandes corpos de infantaria, que, em associação às tropas auxiliares, se mantinham firmes em praças fortificadas, muitas vezes fronteiriças, já não restava muito. Nesta lógica, as cidades nada tinham a temer, o que explica em parte a ausência de sistemas defensivos urbanos alto-imperiais. A partir do século $\mathrm{V}$, porém, as legiões comitatenses actuam sobre o pressuposto de que já não há limes definido, e de que enfrentar o inimigo não implica defender um território.

Conimbriga deve ter empobrecido bastante e rapidamente, neste final de império, ainda mais perante a cidade de Aeminium, que, num período prolongado de escassez, absorvia a maioria dos recursos externos, porque se situava numa posição estratégica mais vantajosa, podendo servir de entreposto territorial mais óbvio do que o seu vizinho. Ainda assim, a lógica agrária romana pode ter conservado algum do seu vigor. Numa sociedade complexa, ainda que enfraquecida, há sempre vontade de moldar o território, organizando-o com maior ou menor sucesso, segundo ideais políticos ou meramente práticos. Roma nunca vira realmente uma distinção entre ambos. Autores como Varrão, Columela e Plínio tinham insistido na utilização social, pedagógica até, da agricultura, e nas suas obras vai transparecendo uma tenacidade quase reaccionária perante um mundo que se desvia da ruralidade tradicional. Fracções desse ideal tipicamente romano ter-se-ão conservado no Baixo Império, e a simbiose entre a cidade e o seu território continuou visível até muito tarde, nomeadamente do ponto de vista religioso, tanto pagão como cristão ${ }^{41}$. Por isso não admira que, enquanto a cidade de Conim briga se reformava drasticamente, tenha existido um plano de agrimen sura simultâneo. Vasco Mantas identificou uma grelha fossilizada, dividida em quatro laterculi, no prolongamento da primeira porta da cidade $^{42}$, pelo que não faz sentido ser anterior ao seu planeamento. Neste possível cadastro não existem indícios que apontem para a existência de casais ou uillae ${ }^{43}$, se exceptuarmos o palacete da Ega com os seus mate-

41 Vide D. Riggs, Paganism Between Cities and Countryside of Late Roman Africa, Urban Centers and Rural Contexts in Late Antiquity (East Lansing, Michigan State University Press 2001).

42 V. Mantas, 'Dois novos miliários do território de Conimbriga', Biblos LXI (1985).

4 * M. Pessoa 'Subsídios para a carta arqueológica do periodo romano na área de Conimbriga', Conimbriga XXV (1986) 53-73.

Faculdade de Letras I Universidade de Coimbra 
riais romanos reaproveitados, mas isso pode decorrer do facto de Condeixa-a-Nova se lhe sobrepor parcialmente. Durante o Baixo Império, são acrescidas funções judiciais à actividade do agrimensor $^{\wedge}$, portanto quem orientava fundações (ou modificações) urbanas actuava também como delegado do poder central. Não seria de estranhar que a cons trução da muralha fosse apenas o aspecto mais visível de uma bem planeada reestruturação urbanística, implicando uma adaptação agrária correspondente.

Entretanto, o forum ter-se-ia, também, alterado. A sua destrui ção pode ter ocorrido apenas duzentos anos mais $\operatorname{tarde}^{44}{ }^{45}$, o que obrigaria a recolocar a datação da obliteração do decumanus primitivo ${ }^{46}$, e novo o eixo, finalmente alinhado, pode ter feito parte de um urbanismo hispanoromano, em vez de ser bárbaro. Há provas de que o centro nevrálgico da ciuitas continuava a desempenhar um papel importante na sociedade, que não se encontrava obrigatoriamente cristianizada. Ainda por cima, é um equívoco que os edifícios cristãos se tenham apoderado, de um momento para o outro, das estruturas pagãs. Pelo contrário, supomos que houve uma grande hesitação, por parte da nova religião, em se associar a sím bolos com os quais não se procurava contacto. Desta forma, o forum esta ria longe da cobiça da Igreja. Em Mérida, o forum, o teatro e o circo continuaram em funcionamento quando, simultaneamente, os edifícios de culto cristãos estavam em actividade 47 * Mas o tom radical com que se tenta combater o paganismo pode nunca ter passado de fachada propa gandística; numa época de recursos menores, a palavra de ordem é recon verter e não destruir. Neste sentido, foi já apontada a carta de Gregorio Magno, a respeito da missão do bispo Agostinho, que tentava converter os Anglos em finais o século VI. Nela torna-se explícita a directiva oficiosa a adoptar: Os lugares sagrados não devem ser destruídos em absoluto [...], mas devem ser destruídos os ídolos que neles haja. [...] Se os mes mos lugares sagrados estão bem construídos, é necessário que esqueçam o culto ao demónio, transform ando-os em reverência ao verdadeiro

44 V. Rosselló, El catastro romano en la España del este y del sur, Estudios sobre centuriaciones romçmas en España (Madrid, Universidad Autónoma de Madrid 1974) 10.

45 J. Alarcão, Conimbriga: 20 anos depois, no prelo.

46 Alarcão e Etienne, op. eit, 167.

47 P. Mateos Cruz, 'E1 urbanismo emeritense en época paleocristiana (ss. V -VI)', in La tradición en la Antigüedad Tardia, Antigüedad y Cristianismo, xIv (Murcia 1997) 604-605.

\section{Faculdade de Letras i Universidade de Coimbra}




\section{Aspectos de Conimbriga Tardo-Antiga}

Deus $^{48}$. Parece óbvio que não existe grande pudor, por detrás do discurso oficial, em tomar conta da logística religiosa pré-cristã. Os conversores sabiam bem que a população-alvo não seria muito receptiva a modifica ções bruscas, sendo por isso conveniente provocar uma associação tran sitória, com base num local já tido como sagrado. Na primeira metade do século V, surge um documento ainda menos preocupado com as aparên cias, sob a forma de sermão e da autoria de S. Pedro Crisólogo. O trecho que importa coloca a boca do próprio Senhor a incitar para que se trans

formem em igrejas os templos, que se convertam em altares as aras ${ }^{49}$

$\mathrm{Na}$ parte ocidental do Império houve sempre um menor ímpeto na aplicação das regras que limitavam os costumes antigos ${ }^{50}$; há manifestações literárias tardias, mais ou menos tímidas, de recuperação de temáticas não cristãs ${ }^{51}$. E S. Martinho de Dume refere-se aos rústicos como atidos ainda à velha superstição dos pagãos, [que] dão seu culto de veneração antes aos demónios que a Deus ${ }^{52}$. O paganus é "aquele que vive no pagus", o que é indicativo da oposição religiosa entre quem habita a cidade e o rústico. A propaganda cristã demorava a penetrar os cam $\operatorname{pos}^{53}$, e os pregadores dos séculos IV e $\mathrm{V}$ tinham a desconfortável cons ciência de que, eles próprios, eram um produto do sistema oratório grecolatino. A retórica, e portanto também a pregação, era uma arte sofisticada, destinada ao consumo do urbanus e não ao do rusticus ${ }^{54}$, mas é óbvio que o proprietário da uilla do Rabaçal, por exemplo, teria bastante mais de "urbano" do que a quase totalidade dos habitantes de Conimbriga. Isto

\section{0}

L. Caballero Zoreda e J. C. Sanchez Santos, Reutilizaciones de material romano en edificios de culto cristiano (Madrid, Museo Arqueológico Nacional 1989) 2-3.

\section{Ibidem.}

50 P. F. Alberto e R. Furtado, Orósio, História Apologética, O livro 7 das Histórias contra os Pagãos e outros excertos, Obras Clássicas da Literatura Portuguesa - Literatura Medieval (Lisboa, Edições Colibri 2000) 13.

51 Em Rutilio Namaciano e Zósimo, por exemplo, vide M. Ribagorda, La pervivenda religiosa pagana en el siglo $V$ : el ejemplo de Rutilio Namaciano, La tradición en la Antigüedad Tardía, Antigüedad y Cristianismo, XIV (Universidad de Murcia 1997) 179-187.

c 9

De Correctione Rusticorum, vide J. M. Garcia, Religiões antigas de PortugalAditamentos e observações As "Religiões da Lusitânia" de Leite de Vasconcelos. Fontes epigráficas (Lisboa, Imprensa Nacional - Casa da Moeda 1991) 181.

o

G. Ch. Picard, 'La société gallo-romaine et son évolution', Les Dossiers de l'Archéologie 59, Histoire et Archéologie (Dijon 1982) 82.

54 E. G Clark, Pastoral Care: Town and Country in Late-Antique Preaching, Urban centers and rural contexts in Late Antiquity (East Lansing, Michigan State University Press 2001) 266-267. 
explica o surgimento de igrejas privadas, ligadas às casas senhoriais do campo, e a respectiva culminação em paróquias rurais.

A organização no quotidiano do Baixo Império modificara-se, pois, de iure mas talvez não tanto de facto. $\mathrm{O}$ princípio das divisões administrativas iria perdurar intacto, em grande parte através da ordem eclesiástica. A conivência imperial permitiu que a sua estrutura adminis trativa, já de si vacilante, se transpusesse gradualmente para o campo da Igreja. Cada governador de província passou a ter de conviver com um arcebispo, e cada prefeito com um bispo. Todos eles se passaram a subju gar, a partir de Diocleciano, ao vicarius das Espanhas (incluindo a Mauritânia $^{55}$ e, mais tarde, as Baleares). O paralelismo entre as hierarquias sempre foi notório, nomeadamente em Isidoro de Sevilha, que via na basílica, supomos que por indução etimológica, a morada dos reis ${ }^{56}$. Ora, o rei dos reis é Deus, e denota-se aí uma alusão à associação das liturgias cristã e imperial. A basílica de Augusta Treverorum transformou-se sem problemas de sala de audiência do palácio imperial em igreja cristã ${ }^{57}$. De facto, esta apropriação formal já estava em curso muito antes de Constan tino, no simbolismo litúrgico e na arquitectura, que não podiam deixar de ser imitações do rito pagão. Em Conimbriga, após a repartição da Penín sula pelos ocupantes bárbaros, houve um período considerável, entre 411 e 585, durante o qual o poder suevo exerceu o seu domínio sobre a região. E completamente impossível isolar essa etapa na sequência material conimbrigense, se exceptuarmos as camadas de destruição atribuídas ao raid de 468. E muito rara a aniquilação total de uma cidade ${ }^{58}$, e a demoli ção de parte das muralhas ${ }^{59}$ aponta, aliás, para um castigo simbólico. As referências directas de Idácio mencionam apenas as destruições dos Sue vos, mas achamos bastante plausível que possa ter havido outras depreda ções, nomeadamente por parte dos Visigodos. Isidoro de Sevilha conta que Teodorico, após ter executado Requiário em 453, regressou da Galécia à Lusitânia, onde se preparava para saquear Mérida, e, só desistindo

55 Diocensis Hispaniarum habet prouincias numero Vil (sic; deve ler-se VI): Beticam, Lusitanicam, Carthaginiensis, Gallecia, Tharraconensis, Mauritania Tingitana; vide Laterculo de Verona 250, XI apud Blazquez, op. cit., 486.

56 W. Sas-Zaloziecky, 'Arte Paleocristã', Ars Mundi 11 (1970) 27.

57 Picard, op. cit., 83.

8 A propos des céramiques de Conimbriga, Mesa-redonda tida em Conimbriga, Conimbriga XIV (Universidade de Coimbra 1975) 76-77.

59 Idácio CCCXI, 241. 
por temor a Santa Eulália, fugiu para a Gália ${ }^{66}$ Ora, é pouco credível que a viagem tivesse como propósito único e final a pilhagem da capital lusi tana. Pelo contrário, após o triunfo em Astorga, o exército vitorioso deve ter assaltado boa parte das cidades menores com que se cruzaram, e isso pode ter incluido Conimbriga, que se situa no caminho mais óbvio para Sul.

Um pouco no seguimento do pensamento de Ferreira de Almeida* 61, parece-nos que o esforço público, durante este período, se deva à estrutura religiosa, e se insere numa lógica paleocristã. De qual quer modo, a ter existido algum empenho arquitectónico politicamente estimulado, teria de ser situado numa época bem posterior. $\mathrm{O}$ próprio facto de as hostes suevas terem atacado a cidade por duas vezes significa que ela, na prática, não estava sob o seu controle. Pagaria um tributo, mas a sua organização continuaria hispano-romana e pós-clássica, caso contrá rio não se percebe que tenha sido tomada in pace decepta ${ }^{62}$ 63. Um dado que reforça esta teoria autonómica é a referência aos embaixadores que, regressando da missão de paz com Teodorico, são reenviados a Conim briga \{remittuntur ad Conimbricam)^. Tranoy entendeu esta visita como urna provisoria tentativa de apaziguamento ${ }^{64}$; lembremo-nos que ela ocorre em 466, um ano após o assalto que despojara os Cantabri. Não seria impossível que a cidade tivesse celebrado um acordo ou um enten dimento tácito com o poder visigodo, o que explicaria que uma mesma missão sueva, após contactos positivos com Teodorico, se deslocasse imediatamente a Conimbriga, com idêntico intuito. Não é determinável se o ataque de 465 fora uma reacção punitiva contra uma cidade limítrofe que pretendia uma aproximação ao reino rival ou se, pelo contrário, os eventuais laços entre Cantaber (que não foi detido juntamente com a família) e a corte visigótica se devam, exactamente, à incursão suévica. Inclinamo-nos para a primeira hipótese, porque a agressão é dirigida contra os dirigentes locais; o esforço diplomático do ano seguinte até pode ter regulamentado a devolução dos reféns. Quando os Suevos, desfeitas as alianças, se mobilizam e pretendem afirmar-se mais niti damente na Lusitania, lançam-se numa expedição que termina em

66 Isidoro 32; vide G. Donini e G. Ford, Isidore of Seville 's Histoiy of the Goths, Vandals, and Suevi (Leiden, E. J. Brill 1970) 16.

61 C. A. Ferreira de Almeida, ‘Arte paleocristã da época das invasões’, in História da Arte em Portugal II (Lisboa, Alfa 1988) 21.

62 Idácio CCCXI, 229.

63 Idácio CCCXI, 231.

64 Tranoy 1974:122. 


\section{Adriaan de Man}

Vlixipona em 46965, e é nessa movimentação que se compreende a última tomada documentada de Conimbriga.

O domínio visigótico constitui uma etapa arquitectónica paleo-cristã seguinte, e bem diferenciada, ao divulgar fórmulas decorativas específicas. $O$ facto de ter culminado numa determinada ordem foi inde pendente da vigência política bárbara, e a arte, que não era nova, mas sim romana, aparecia apenas transfigurada. Se descontarmos algum exagero literário faccioso, houve sempre, por parte de uma razoável parte da elite esclarecida, a ideia de que os Visigodos eram, ou podiam ser, os renova dores e protectores da antiga Roma. Idácio acaba por tratá-los como trai dores, mas nem Isidoro de Sevilha, nem Cassiodoro vêem inconveniente no domínio godo do Ocidente ${ }^{66}$.

65 Idácio CCCXIl, 246.

66 M. A. Wes, 'Das Ende des Kaisertums im Westen des Römischen Reichs', Archeologische Studien van het Nederlands Historisch Instituut te Rome deel II (Staatsdruckerei, 's-Gravenhage 1967) 174. 